\title{
SISTEM PENDUKUNG KEPUTUSAN PENERIMAAN BEASISWA PADA SMP NEGERI 2 PADANG DENGAN MENGGUNAKAN METODE TECHNIQUE FOR ORDER OF PREFERENCE BY SIMILARITY TO IDEAL SOLUTION MENGGUNAKAN PEMOGRAMAN PHP DAN MYSQL
}

\author{
Harkamsyah Andrianof \\ Universitas Putra Indonesia "YPTK" Padang \\ e-mail: harkamsyah.andrianof@upiyptk.ac.id
}

\begin{abstract}
Assisted Decision System adalah satu intelektual dari sumber daya manusia dan kemampuan sebuah komputer untuk mengoreksi suatu keputusan untuk membantu atau menggantinya secara umum, oleh karena itu sistem ini akan memberikan keputusan yang tepat dan akurat dalam mengatur data beasiswa bagi mereka yang benar-benar berhak untuk menerimanya. Teknik untuk Urutan Preferensi dengan Kemiripan dengan Solusi Ideal adalah metode yang memiliki konsep alternatif pilihan terbaik. Tidak hanya memiliki interval terpendek dari solusi ideal positif, tetapi juga memiliki interval terpanjang dari yang negatif. Kriteria yang digunakan dalam sistem ini adalah variabel sesuai dengan beasiswa yang disediakan oleh Institusion.
\end{abstract}

Kata Kunci: SPK, TOPSIS, Beasiswa

\begin{abstract}
Assisted Decision System is an intellectual from human resource and computer capabilities to correct decisions in helping or replacing it in general, therefore the system will give a precise and accurate decisions in organizing scholarship data for them who really worth. Technique For Order Of Preference By Similarity To Ideal Solution is a method that had a concepts which the best chosen alternative. Not only has shortest interval from positive ideal solution, but also has the longest interval from the negative one. Used criteria in this system is variable according to scholarship provided by Institusion.
\end{abstract}

Keywords: SPK,TOPSIS,Beasiswa

\section{Pendahuluan}

\subsection{Latar Belakang Masalah}

Beasiswa merupakan pemberian bantuan berupa keuangan kepada perorangan yang membutuhkan untuk keberlangsungan pendidikan yang sedang ditempuh, beasiswa juga merupakan bantuan untuk perorangan yang berprestasi untuk melanjutkan pendidikannya. Penetapan penerima beasiswa yang ditentukan oleh pihak sekolah ini yang membuat terkadang pemilihan penerima beasiswa dipilih secara subjektif, dimana penerima beasiswa tidak sesuai dengan kriteria yang ditentukan. manual dengan kriteria yang ada menyebabkan kurang efektif dan menjadi subyektifitas dalam melakukan pemilihan yang berhak mendapat beasiswa [1]. 
Dengan semakin banyaknya pemohon beasiswa, menjadikan tantangan bagi pihak SMP Negeri 2 Padang untuk dapat memberikan suatu keputusan yang tepat, dan akurat dalam pengelolaan data penerima besiswa yang benar-benar berhak menerima beasiswa. Dalam hal ini terdapat beberapa masalah yang sedang terjadi dalam pemberian beasiswa kepada siswa, yaitu seperti sekolah SMP Negeri 2 padang masih menggunakan cara yang manual untuk menentukan peserta didik yang berhak dalam menerima beasiswa yang sampai ke sekolah, kurangnya komunikasi antara siswa dengan wali kelas tentang keadaan keluarga dan penyeleksian yang kurang ketat kepada siswa.

Hal ini mengakibatkan pengolahan data yang kurang efektif, membutuhkan waktu yang relatif lama, sehingga sering terjadi subjektifitas dari para pengambil keputusan. Untuk mempermudah proses dalam menentukan peserta didik yang berhak menerima beasiwa, maka perlu adanya diciptakan suatu sistem rekomendasi yang berfungsi untuk mempermudah dalam membantu melakukan seleksi kepada para calon penerima beasiswa. Sistem untuk rekomendasi pemberian beasiswa adalah menggunakan sistem pendukung keputusan yang berfungsi dalam membantu pengurus sekolah melakukan penyeleksian terhadap calon penerima beasiswa yaitu dengan metode Technique for Order Preference by Similarity to Ideal Solution (TOPSIS), PHP dan MySQL [8].

\section{LANDASAN TEORI}

Pengambilan keputusan merupakan suatu tindakan yang dilakukan sesorang dalam mengambil sebuah langkah atau keputusan. Dalam kata lain merupakan bentuk pemilihan dari berbagai alternatif tindakan yang mungkin dipilih dan prosesnya melalui mekanisme tertentu, dengan harapan akan menghasilkan suatu keputusan yang terbaik. Retno Sari [2]. mengemukakan bahwa sistem pendukung keputusan sebagai berbasis komputer terdiri dari tiga komponen yang saling berineteraksi, yaitu sistem Bahasa, sistem pengetahuan, dan sistem pemprosesan masalah (hubungan antara dua komponen lainnya, yang terdiri dari satu atau lebih kapabilitas manipulasi masalah umum yang diperlukan dalam pengambilan sebuah keputusan [7]. Keputusa memiliki beberapa tujuan yaitu: membantu seseorang membuat keputusan untuk memecahkan masalah semiterstruktur, mendukung penilaian dalam suatu hal.

Beasiswa adalah suatu pemberian berupa keuangan kepada seseorang yang tidak mampu atau yang berprstasi. Dalam hal lain beasiswa merupakan penghasilan bagi yang menerimanya. Hal ini sesuai dengan ketentuan pasal 4 ayat (1) $\mathrm{UU} \mathrm{PPh} / 2000$ disebutkan pengertian penghasilan adalah tambahan kemampuan ekonomis dengan nama dan dalam bentuk apa pun yang akan diterima atau diperoleh dari sumber Indonesia atau luar Indonesia sehingga dapat digunakan untuk dikonsumsi atau menambah kekayaan Wajib Pajak. Karena beasiswa bisa diartikan sebagai hal untuk menambah kemampuan ekonomis bagi penerimanya, berarti beasiswa merupakan sebuah penghasilan. [3].

Technique For Order Preference By Similarity To Ideal Solution merupakan metode yang digunakan dalam pengambilan keputusan beasiswa, yaitu sebuah metode yang bisa membantu dalam proses pengambilan satu keputusan yang optimal dalam menyelesaikan suatu masalah keputusan secara praktis [6]. Hal ini disebabkan karena konsepnya yang sederhana dan sangat mudah untuk dipahami, dan komputasinya efisien 
serta memiliki kemampuan untuk mengukur kinerja yang relatif dari alternatif-alternatif keputusan dari bentuk matematis sederhana. [4].

Tahapan penyelesaian dengan metode topsis adalah sebagai berikut:

1. Menentukan normalisasi matriks keputusan.

Nilai ternomalisasi rij dihitung dengan rumus:

$$
r_{i j}=\frac{x_{i j}}{\sqrt{\sum_{i=1}^{m} x_{i j}^{2}}} \quad \text { dengan } \mathrm{i}=1,2, \ldots, \mathrm{m} ; \text { dan } \mathrm{j}=1,2, \ldots, \mathrm{n} .
$$

2. Menentukan bobot ternomalisasi matriks keputusan.

Solusi ideal positif $\mathrm{A}^{+}$dan solusi ideal negative $\mathrm{A}^{-}$dapat ditentukan berdasarkan bobot ternormalisasi $\left(\mathrm{y}_{\mathrm{ij}}\right)$ sebagai :

$$
\begin{aligned}
& \boldsymbol{Y}_{i j}=\boldsymbol{w}_{i} \boldsymbol{r}_{i j} \\
& A^{+}=\left(y_{1}{ }^{+}, y_{2}{ }^{+}, \ldots, y_{n}{ }^{+}\right) \\
& A^{-}=\left(y_{1}, y_{2}, \ldots, y_{n}{ }^{-}\right)
\end{aligned}
$$

3. Jarak antar alternative Ai dengan solusi ideal positif

Dirumuskan sebagai berikut :

$$
\left.D_{i}^{+}=\sqrt{\sum_{j=1}^{n}\left(y_{i}^{+}\right.}-y_{i j}\right)^{2} ; \quad \mathrm{i}=1,2, \ldots, \mathrm{m} .
$$

4. Jarak antara alternative Ai dengan solusi ideal negative

Dirumuskan sebagai berikut :

$$
D_{i}^{-}=\sqrt{\sum_{j=1}^{n}\left(y_{i j}-y_{i}^{-}\right)^{2}} ; \quad \mathrm{i}=1,2, \ldots, \mathrm{m} .
$$

5. Nilai prefensi untuk setiap alternative (Vi)

Dirumuskan sebagai berikut :

$V_{i}=\frac{D_{i}^{-}}{D_{i}^{-}+D_{i}^{+}}$

Nilai $\mathrm{V}_{\mathrm{i}}$ yang lebih besar menunjukkan alternative $\mathrm{A}_{\mathrm{i}}$ lebih dipilih. [5].

\section{ANALISA DAN PERANCANGAN}

\subsection{Analisa Sistem}

Analisa Sistem Analisa sistem merupakan suatu kegiatan yang dilakukan bertujuan untuk mengetahui permasalahan-permasalahan serta kendala-kendala yang sering terjadi pada sistem untuk dapat dilakukan perbaikan.

Pada tahapan analisa sistem kebutuhan-kebutuhan pengguna didefenisikan untuk mempermudah dalam melakukan perncangan, yang dilakukan sebelum melakukan perancangan sistem baru. Analisa sistem dilakukan agar permasalahan yang ada dapat diketahui, sehingga analisa permasalahan yang ditemukan dapat dirumuskan pemecahan permasalahannya. 


\subsection{Perhitugan Metode TOPSIS}

Perhitungan metode TOPSIS merupakan langkah-langkah yang dilakukan untuk mencari perhitungan alternatif terbaik melalui beberapa faktor yang beragam,langkahlangkah metode TOPSIS diantaranya yaitu :

\subsubsection{Kriteria}

Tahapan awal pada penerapan perhitungan metode TOPSIS ini yaitu menetukan kriteria penyeleksian penerimaan beasiswa. Dalam penelitian ini ada beberapa kriteriakriteria yang digunakan untuk proses seleksi yaitu dapat dilihat pada Tabel 3.1 ini :

Tabel 3.1 Kriteria

\begin{tabular}{|l|l|}
\hline No. & Kriteria \\
\hline A. & Akademik \\
\hline 1. & Rata-Rata Nilai Rapor \\
\hline 2. & Ranking Kelas \\
\hline B. $\quad$ Pribadi \\
\hline $3 . \quad$ & Kepribadian \\
\hline $4 . \quad$ & Akhlak \\
\hline C. $\quad$ Potensi \\
\hline $5 . \quad$ & Prestasi Bidang Lain \\
\hline
\end{tabular}

\subsubsection{Alternatif}

Tahapan selanjutnya yaitu melakukan perangkingan setiap alternatif terhadap setiap kriteria yang ada dengan penilaian 1 sampai dengan 5 yaitu dengan ketentuan :

$1=$ Sangat Buruk

$2=$ Buruk

$3=$ Cukup

4 = Baik

5 = Sangat Baik

Perangkingan alternatif yang dilakukan dapat dilihat pada Tabel 3.2 berikut ini :

Tabel 3.2 Perangkingan Alternatif

\begin{tabular}{|c|c|c|c|}
\hline No. & Kriteria & $\begin{array}{c}\text { Rentang } \\
\text { Data }\end{array}$ & Rangking \\
\hline \multirow[t]{5}{*}{1.} & \multirow{5}{*}{$\begin{array}{l}\text { Rata-Rata } \\
\text { Nilai Rafor }\end{array}$} & $0-45$ & 1 \\
\hline & & $46-55$ & 2 \\
\hline & & $56-65$ & 3 \\
\hline & & $66-85$ & 4 \\
\hline & & $86-100$ & 5 \\
\hline \multirow[t]{5}{*}{2.} & \multirow{5}{*}{$\begin{array}{l}\text { Ranking } \\
\text { Kelas }\end{array}$} & $9-10$ & 1 \\
\hline & & $7-8$ & 2 \\
\hline & & $5-6$ & 3 \\
\hline & & $3-4$ & 4 \\
\hline & & $1-2$ & 5 \\
\hline \multirow[t]{2}{*}{3} & \multirow[t]{2}{*}{ Kepribadian } & $\mathrm{E}$ & 1 \\
\hline & & $\mathrm{D}$ & 2 \\
\hline
\end{tabular}




\begin{tabular}{|c|c|c|c|}
\hline & & $\mathrm{C}$ & 3 \\
\hline & & B & 4 \\
\hline & & $\mathrm{A}$ & 5 \\
\hline \multirow[t]{5}{*}{4.} & \multirow[t]{5}{*}{ Akhlak } & $\mathrm{E}$ & 1 \\
\hline & & $\mathrm{D}$ & 2 \\
\hline & & $\mathrm{C}$ & 3 \\
\hline & & B & 4 \\
\hline & & A & 5 \\
\hline \multirow[t]{5}{*}{5.} & \multirow{5}{*}{$\begin{array}{l}\text { Prestasi } \\
\text { Bidang } \\
\text { Lain }\end{array}$} & 0 & 1 \\
\hline & & 1 & 2 \\
\hline & & $2-4$ & 3 \\
\hline & & $5-6$ & 4 \\
\hline & & $>6$ & 5 \\
\hline
\end{tabular}

Tabel 3.6 Hasil Matrik Keputusan

\begin{tabular}{|c|c|c|c|c|c|}
\hline (0) & $K_{I}(1)$ & $K_{2}(2)$ & $K_{3}(\mathbf{3})$ & $K_{4}(4)$ & $K_{5}(5)$ \\
\hline$A_{1}$ & 5 & 5 & 5 & 5 & 2 \\
\hline$A_{2}$ & 5 & 5 & 5 & 4 & 2 \\
\hline$A_{3}$ & 5 & 5 & 4 & 4 & 1 \\
\hline$A_{4}$ & 5 & 5 & 4 & 4 & 2 \\
\hline$A_{5}$ & 5 & 4 & 4 & 4 & 1 \\
\hline$A_{6}$ & 5 & 5 & 4 & 4 & 1 \\
\hline$A_{7}$ & 5 & 5 & 5 & 5 & 2 \\
\hline$A_{8}$ & 5 & 4 & 4 & 4 & 1 \\
\hline (0) & (1) & (2) & (3) & (4) & (5) \\
\hline$A_{9}$ & 5 & 4 & 4 & 4 & 1 \\
\hline$A_{10}$ & 5 & 5 & 4 & 4 & 2 \\
\hline$A_{11}$ & 5 & 5 & 4 & 4 & 1 \\
\hline$A_{12}$ & 5 & 5 & 4 & 4 & 2 \\
\hline$A_{13}$ & 5 & 5 & 4 & 4 & 1 \\
\hline$A_{14}$ & 5 & 5 & 5 & 5 & 1 \\
\hline$A_{15}$ & 4 & 4 & 5 & 5 & 1 \\
\hline
\end{tabular}

\subsubsection{Matrik Keputusan Ternormalisasi}

Setelah matrik keputusan dan bobot kriteria didapat, maka selanjutnya yaitu mencari nilai bobot pembagi untuk menentukan matrik ternormalisasi. Adapun bobot pembagi didapat menggunakan rumus 3.1 sebagai berikut:

$$
R i j=\frac{X i j}{\sqrt{\int_{i}^{m}=1^{x^{2} i j}}}
$$

Dimana :

$R_{i j} \quad$ adalah elemen matrik keputusan yang ternormalisasi.

$R, X_{i j} \quad$ adalah elemen matrik keputusan. 
Perhitungan matrik keputusan ternormalisasi dapat dilihat pada penyelesaian berikut ini:

Tabel 3.9 Hasil Matrik Keputusan Ternormalisasi Terbobot

\begin{tabular}{|c|c|c|c|c|c|}
\hline Alternatif & $\boldsymbol{K}_{\boldsymbol{I}}$ & $\boldsymbol{K}_{\boldsymbol{2}}$ & $\boldsymbol{K}_{\boldsymbol{3}}$ & $\boldsymbol{K}_{\boldsymbol{4}}$ & $\boldsymbol{K}_{\boldsymbol{5}}$ \\
\hline $\boldsymbol{A}_{\boldsymbol{1}}$ & 1,307 & 1,358 & 1,481 & 1,505 & 0,696 \\
\hline $\boldsymbol{A}_{\boldsymbol{2}}$ & 1,307 & 1,358 & 1,481 & 0,963 & 0,696 \\
\hline $\boldsymbol{A}_{\boldsymbol{3}}$ & 1,307 & 1,358 & 0,948 & 0,963 & 0,174 \\
\hline $\boldsymbol{A}_{\boldsymbol{4}}$ & 1,307 & 1,358 & 0,948 & 0,963 & 0,696 \\
\hline $\boldsymbol{A}_{\boldsymbol{5}}$ & 1,307 & 0,869 & 0,948 & 0,963 & 0,174 \\
\hline $\boldsymbol{A}_{\boldsymbol{6}}$ & 1,307 & 1,358 & 0,948 & 0,963 & 0,174 \\
\hline $\boldsymbol{A}_{\boldsymbol{7}}$ & 1,307 & 1,358 & 1,481 & 1,505 & 0,696 \\
\hline $\boldsymbol{A}_{\boldsymbol{8}}$ & 1,307 & 0,869 & 0,948 & 0,963 & 0,174 \\
\hline $\boldsymbol{A}_{\boldsymbol{9}}$ & 1,307 & 0,869 & 0,948 & 0,963 & 0,174 \\
\hline $\boldsymbol{A}_{\boldsymbol{1 0}}$ & 1,307 & 1,358 & 0,948 & 0,963 & 0,696 \\
\hline $\boldsymbol{A}_{\boldsymbol{1 1}}$ & 1,307 & 1,358 & 0,948 & 0,963 & 0,174 \\
\hline $\boldsymbol{A}_{\boldsymbol{1 2}}$ & 1,307 & 1,358 & 0,948 & 0,963 & 0,696 \\
\hline $\boldsymbol{A}_{\boldsymbol{1 3}}$ & 1,307 & 1,358 & 0,948 & 0,963 & 0,174 \\
\hline $\boldsymbol{A}_{\boldsymbol{1 4}}$ & 1,307 & 1,358 & 1,481 & 1,505 & 0,174 \\
\hline $\boldsymbol{A}_{\boldsymbol{1 5}}$ & 0,836 & 0,869 & 1,481 & 1,505 & 0,174 \\
\hline
\end{tabular}

\subsubsection{Matrik Solusi Ideal Positif dan Matrik Solusi Ideal Negatif}

Tabel 3.10 Matrik Keputusan Nilai Max dan nilai Min

\begin{tabular}{|c|c|c|c|c|c|}
\hline Alternatif & $\boldsymbol{K}_{\boldsymbol{1}}$ & $\boldsymbol{K}_{\boldsymbol{2}}$ & $\boldsymbol{K}_{\boldsymbol{3}}$ & $\boldsymbol{K}_{\boldsymbol{4}}$ & $\boldsymbol{K}_{\boldsymbol{5}}$ \\
\hline $\boldsymbol{A}_{\boldsymbol{1}}$ & 1,307 & 1,358 & 1,481 & 1,505 & 0,696 \\
\hline $\boldsymbol{A}_{\boldsymbol{2}}$ & 1,307 & 1,358 & 1,481 & 0,963 & 0,696 \\
\hline $\boldsymbol{A}_{\boldsymbol{3}}$ & 1,307 & 1,358 & 0,948 & 0,963 & 0,174 \\
\hline $\boldsymbol{A}_{\boldsymbol{4}}$ & 1,307 & 1,358 & 0,948 & 0,963 & 0,696 \\
\hline $\boldsymbol{A}_{\boldsymbol{5}}$ & 1,307 & 0,869 & 0,948 & 0,963 & 0,174 \\
\hline $\boldsymbol{A}_{\boldsymbol{6}}$ & 1,307 & 1,358 & 0,948 & 0,963 & 0,174 \\
\hline $\boldsymbol{A}_{\boldsymbol{7}}$ & 1,307 & 1,358 & 1,481 & 1,505 & 0,696 \\
\hline $\boldsymbol{A}_{\boldsymbol{8}}$ & 1,307 & 0,869 & 0,948 & 0,963 & 0,174 \\
\hline $\boldsymbol{A}_{\boldsymbol{9}}$ & 1,307 & 0,869 & 0,948 & 0,963 & 0,174 \\
\hline $\boldsymbol{A}_{\boldsymbol{1 0}}$ & 1,307 & 1,358 & 0,948 & 0,963 & 0,696 \\
\hline
\end{tabular}




\begin{tabular}{|c|c|c|c|c|c|}
\hline $\boldsymbol{A}_{11}$ & 1,307 & 1,358 & 0,948 & 0,963 & 0,174 \\
\hline $\boldsymbol{A}_{12}$ & 1,307 & 1,358 & 0,948 & 0,963 & 0,696 \\
\hline $\boldsymbol{A}_{13}$ & 1,307 & 1,358 & 0,948 & 0,963 & 0,174 \\
\hline $\boldsymbol{A}_{14}$ & 1,307 & 1,358 & 1,481 & 1,505 & 0,174 \\
\hline $\boldsymbol{A}_{15}$ & 0,836 & 0,869 & 1,481 & 1,505 & 0,174 \\
\hline $\operatorname{Max}\left(\mathbf{A}^{+}\right)$ & $\mathbf{1 , 3 0 7}$ & $\mathbf{1 , 3 5 8}$ & $\mathbf{1 , 4 8 1}$ & $\mathbf{1 , 5 0 5}$ & $\mathbf{0 , 6 9 6}$ \\
\hline $\operatorname{Min}\left(\mathbf{A}^{-}\right)$ & $\mathbf{0 , 8 3 6}$ & $\mathbf{0 , 8 6 9}$ & $\mathbf{0 , 9 4 8}$ & $\mathbf{0 , 9 6 3}$ & $\mathbf{0 , 1 7 4}$ \\
\hline
\end{tabular}

3.2.5 Menghitung Jarak Alternatif Solusi Ideal Positif dan Solusi Ideal Negatif

Tabel 3.13 Hasil Jarak Alternatif Solusi Ideal Positif

\begin{tabular}{|c|c|}
\hline $\begin{array}{c}\text { Alternatif } \\
(\mathbf{1})\end{array}$ & $\begin{array}{c}\mathbf{S}^{+} \\
\mathbf{2})\end{array}$ \\
\hline$\alpha_{1}$ & 0 \\
\hline$\alpha_{2}$ & 0,542 \\
\hline$\alpha_{3}$ & 0,922 \\
\hline$\alpha_{4}$ & 0,760 \\
\hline$\alpha_{5}$ & 1,044 \\
\hline$\alpha_{6}$ & 0,922 \\
\hline$\alpha_{7}$ & 0 \\
\hline$\alpha_{8}$ & 1,044 \\
\hline$\alpha_{9}$ & 1,044 \\
\hline$\alpha_{10}$ & 0,760 \\
\hline$(\mathbf{1})$ & $\mathbf{2})$ \\
\hline$\alpha_{11}$ & 0,922 \\
\hline$\alpha_{12}$ & 0,760 \\
\hline$\alpha_{13}$ & 0,922 \\
\hline$\alpha_{14}$ & 0,522 \\
\hline$\alpha_{15}$ & 0,856 \\
\hline
\end{tabular}

Tabel 3.14 Hasil Jarak Alternatif Solusi Ideal Negatif

\begin{tabular}{|c|c|}
\hline Alternatif & $\mathbf{S}^{+}$ \\
\hline$\alpha_{1}$ & 1,145 \\
\hline$\alpha_{2}$ & 1,009 \\
\hline$\alpha_{3}$ & 0,679 \\
\hline$\alpha_{4}$ & 0,856 \\
\hline$\alpha_{5}$ & 0,471 \\
\hline$\alpha_{6}$ & 0,679 \\
\hline$\alpha_{7}$ & 1,145 \\
\hline$\alpha_{8}$ & 0,471 \\
\hline$\alpha_{9}$ & 0,471 \\
\hline$\alpha_{10}$ & 0,856 \\
\hline$\alpha_{11}$ & 0,679 \\
\hline$\alpha_{12}$ & 0,856 \\
\hline
\end{tabular}




\begin{tabular}{|c|c|}
\hline$\alpha_{13}$ & 0,679 \\
\hline$\alpha_{14}$ & 1,019 \\
\hline$\alpha_{15}$ & 0,760 \\
\hline
\end{tabular}

\subsubsection{Menghitung Kedekatan Relatif Terhadap Solusi Ideal}

Tabel 3.16 Hasil Nilai $\mathrm{C}^{+}$

\begin{tabular}{|c|c|c|}
\hline $\begin{array}{l}\text { No } \\
\text { (1) }\end{array}$ & $\begin{array}{c}\text { Alternatif } \\
\text { (2) }\end{array}$ & $\begin{array}{l}\mathbf{C}^{+} \\
(3)\end{array}$ \\
\hline 1 & $\begin{array}{l}\text { ATHIYAH } \\
\text { MARDATILLAH }\end{array}$ & 1 \\
\hline 2 & ALFI SYAHRI & 0,650 \\
\hline 3 & DEANA FITRIYANI & 0,424 \\
\hline 4 & JAKA ANUGRAH & 0,530 \\
\hline 5 & $\begin{array}{l}\text { JEFRIAGIL } \\
\text { ARDIANSYAH }\end{array}$ & 0,311 \\
\hline 6 & FITRI HANDAYANI & 0,424 \\
\hline 7 & $\begin{array}{ll}\text { HESTI } & \text { PERMATA } \\
\text { YANDA } & \end{array}$ & 1 \\
\hline (1) & $(2)$ & (3) \\
\hline 8 & IRMA SURYANI & 0,311 \\
\hline 9 & SELFIA GUSTINA & 0,311 \\
\hline 10 & SILVI YULIANI & 0,530 \\
\hline 11 & $\begin{array}{l}\text { MAZAYA HULWANA } \\
\text { S.P }\end{array}$ & 0,424 \\
\hline 12 & $\begin{array}{l}\text { MUTIARA } \\
\text { RAMADAHANI }\end{array}$ & 0,530 \\
\hline 13 & $\begin{array}{l}\text { RAHMI } \\
\text { PUTRI }\end{array}$ & 0,424 \\
\hline 14 & YULDEFITA SUSANTI & 0,661 \\
\hline 15 & ZARI AYU NOFITA & 0,470 \\
\hline
\end{tabular}

1. Use case diagram

Use case diagram menjelaskan tentang manfaat dari aplikasi jika dilihat dari sudut pandang orang yang berada diluar sistem (aktor)[8]. Diagram ini dapat menunjukkan fungsionalitas sebuah sistem atau kelas dan bagaimana sistem berinteraksi dengan dunia luar. Use case diagram dapat digunakan selama proses analisa untuk menangkap permintaan terhadap sistem dan untuk memahami bagaimana sistem tersebut harus bekerja [10] . Pada aplikasi sistem penunjang keputusan juga berfungsi sama yaitu untuk menjelaskan fungsi yang terdapat pada setiap aktor, dapat dilihat pada Gambar 3.1 berikut ini: 


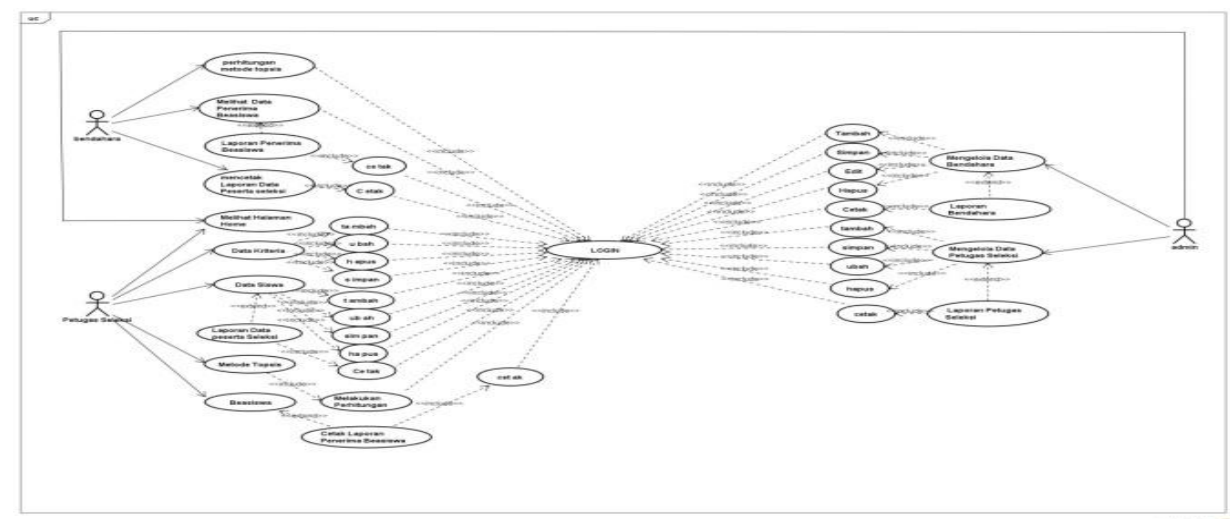

Gambar 3.1 Usecase Diagram

\subsubsection{Class Diagram}

Class Diagram adalah sebuah spesifikasi yang akan menghasilkan sebuah objek dan merupakan inti dari pengembangan dan desain berorientasi objek [9]. Adapun interaaksi hubungan antara satu sama lain dapat dimati berdasarkan gambar Class Diagram sistem pendukung keputusan dalam menggunakan metode TOPSIS pada SMP N 2 Padang dibawah ini sesuai pada gambar 3.12:

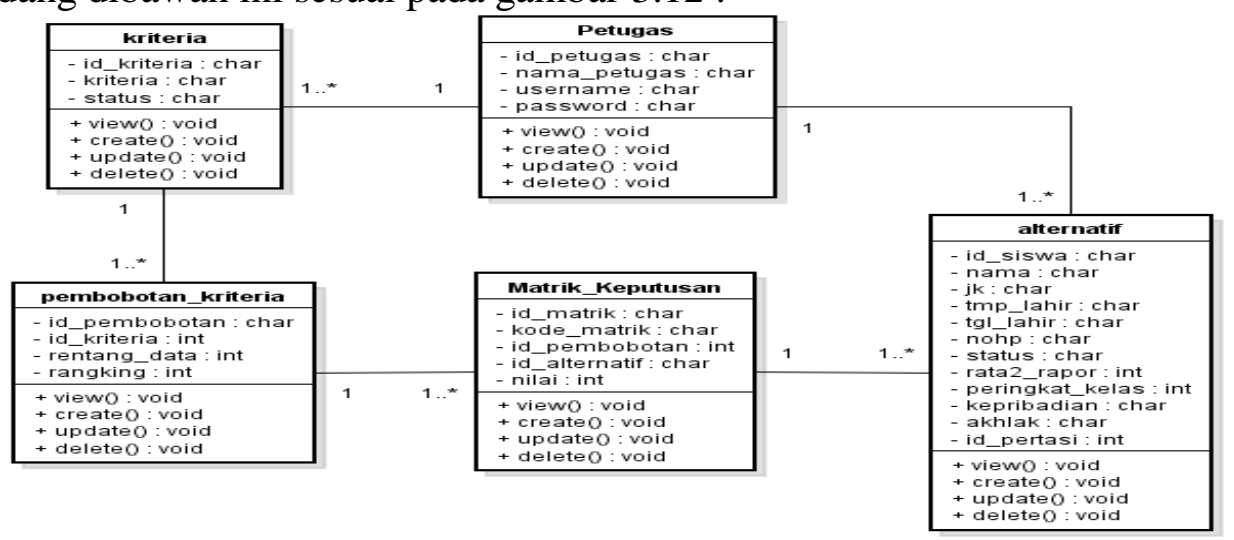

Gambar 3.2 Class Diagram

\section{IMPLEMENTASI SISTEM}

\subsection{Implementasi Sistem}

Tahap implementasi adalah tahap dimana sistem informasi telah digunakan oleh pengguna. Pada tahap ini peneliti diharuskan melakukan penetapan aplikasi yang sedang dibangun pada sebuah sistem, tahap implementasi ini dilakukan setelah melalui tahap perencanaan, tujuan implementasi ini adalah untuk mengetahui sejauh mana aplikasi pada sistem dapat digunakan.

\subsection{Instalasi Software}

Dalam tahap Implementasi dan perancangan sistem dibutuhkan software pendukung yang akan digunakan sebagai alat bantu untuk mengetahui hasil dari sistem yang sudah dibuat dan digunakan juga sebagai media bantu untuk penyimpanan data yang telah diinputkan dari sistem tersebut.berikut adalah beberapa software penukung yang penulis gunakan. 


\subsection{Pengujian Sistem}

Tahap pengujian sistem merupakan tahap agar sistem penunjang keputusan siap untuk digunakan.dalam tahap ini berlangsung beberapa aktifitas secara bertahap yaitu mulai dari menerapkan rencana impelmentasi, melakukan kegiatan implementasi dan tindak lanjut impelamentasi.

\subsubsection{Tampilan Halaman Laporan Peserta Seleksi}

Form laporan data peserta seleksi berisi data siswa yang telah diinputkan petugas ke sistem. Bentuk tampilan laporan peserta seleksi seperti pada gambar 3.40 :

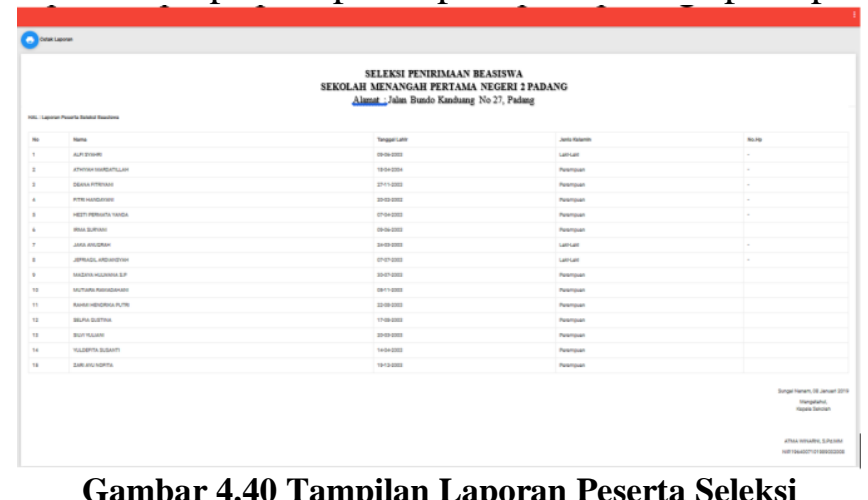

\subsubsection{Tampilan Halaman Laporan Data Penerima Beasiswa}

Form laporan data penerima beasiswa berisi data siswa yang telah terpilih mendapatkan beasiswa melalui proses perhitungan pada metode topsis yang diinputkan oleh petugas ke sistem. Bentuk tampilan laporan data penerima beasiswa seperti pada gambar 3.41 :

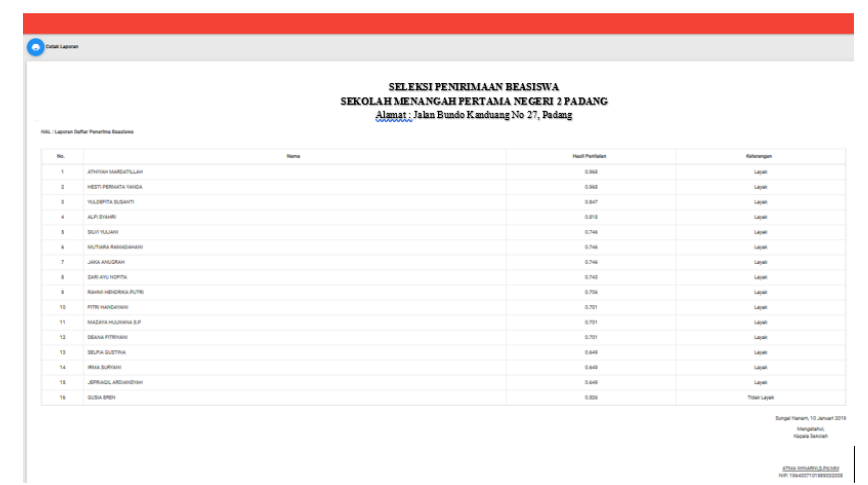

Gambar 4.41 Tampilan Laporan Data Penerima Beasiswa

\subsubsection{Tampilan Halaman Laporan Data Bendahara}

Form laporan data bendahara berisi data diri bendahara yang telah diinputkan admin ke sistem. Bentuk tampilan laporan data bendahara seperti pada gambar 3.42 : 


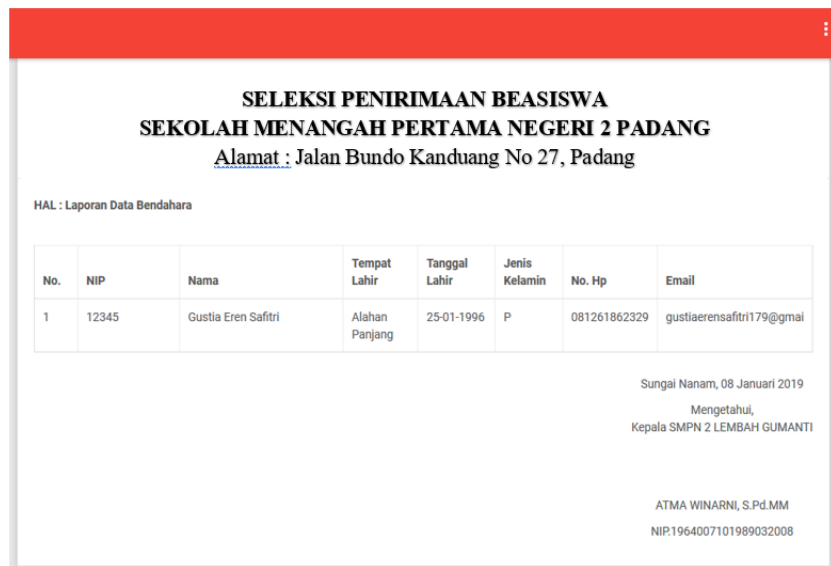

Gambar 4.42 Tampilan Laporan Bendahara

\subsubsection{Tampilan Halaman laporan Data Petugas Seleksi}

Form laporan data petugas seleksi berisi data diri petugas seleksi yang telah diinputkan oleh admin ke sistem. Bentuk tampilan laporan peserta seleksi seperti pada gambar 3.43 :

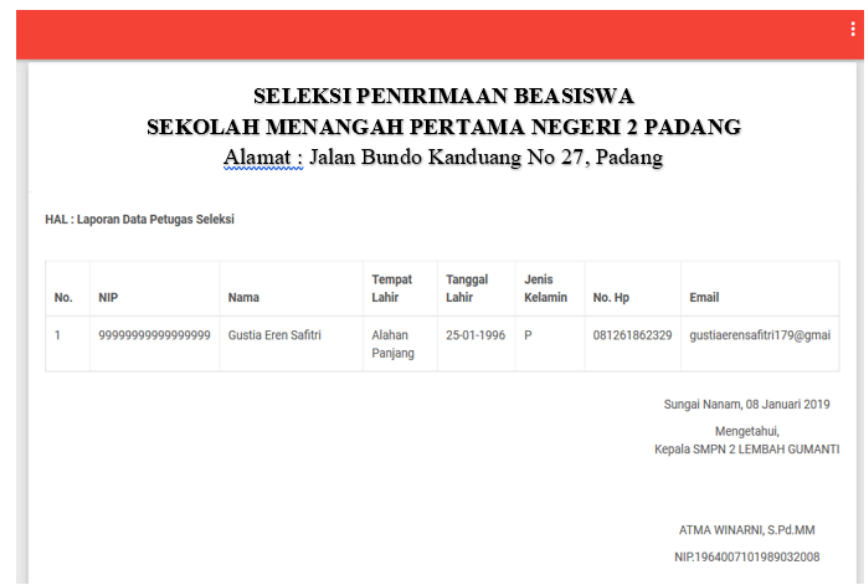

Gambar 4.43 Tampilan Laporan Petugas Seleksi

\section{PENUTUP}

\subsection{Kesimpulan}

Berdasarkan dari sebuah penelitian yang dilakukan oleh peneliti, dan dari hipotesa yang ditemukan sebelumnya serta didukung oleh landasan teori dan analisa, maka dapat diambil kesimpulan sebagai berikut :

1. Dengan cara mengimpementasikan sistem pendukung keputusan dengan metode TOPSIS proses penyeleksian penerimaan beasiswa di SMPN 2 Padang dapat memberikan hasil yang lebih akurat.

2. Dengan adanya pemograman PHP dan Mysql dapat digunakan untuk membangun sistem pendukung keputusan metode TOPSIS dalam bentuk aplikasi yang dapat diimplementasikan di SMP Negeri 2 Padang agar dapat membantu proses penyeleksian menjadi lebih mudah,cepat dan tepat.

3. Dengan adanya sistem pendukung keputusan metode TOPSIS menggunakan bahasa pemograman PHP dan database Mysql pembuatan laporan dapat 
dikerjakan dengan lebih mudah dan proses penyeleksian penerima beasiswa dapat dilakukan dengan cepat serta hasil yang akurat .

\subsection{Saran}

Adapun saran-saran yang disampaikan berdasarkan hasil analisa dan pengamatan penulis di SMP Negeri 2 Padang dalam upaya meningkatkan efektifitas dan efisiensi kerja adalah sebagai berikut :

1. Agar sistem yang dirancang dapat bekerja secara efektif dan efesien maka diperlukannya tenaga yang terampil dalam pengolahan aplikasi yang dibuat dengan melakukan pengenalan dan pelatihan terhadap karyawan yang terlibat dengan sistem yang diterapkan, minimal karyawan tersebut mengetahui dan mengerti tentang sistem yang baru diterapkan.

2. Perubahan dari sistem yang lama ke sistem yang baru ini dapat dilakukan secara bertahap. Apabila sistem yang baru sudah berjalan dengan baik maka, sistem yang lama dapat ditinggalkan atau juga dapat dijalankan untuk menghindari adanya kerusakan yang fatal pada sistem yang baru.

3. Rancangan sistem aplikasi ini juga bisa dikembangkan atau dimodifikasi sesuai dengan kasus yang dibutuhkan.

4. Bagi pengguna yang tidak mengerti metode Topsis akan sedikit sulit dalam menggunakan aplikasi sistem pendukung keputusan ini maka diperlukan sedikit pelatihan untuk mengenalkan bagaimana proses atau cara kerja dari sistem ini.

5. Kriteria yang terdapat didalam aplikasi ini masih memiliki keterbatasan sebaiknya untuk pengembangan selanjutnya kriteria ditambahkan secara lebih detail. 


\section{DAFTAR PUSTAKA}

[1] A.S, R., \& M, S. (2018). Rekayasa Perangkat Lunak. Informatika Bandung.

[2] Eka Iswandy. (2015). Sistem Penunjang Keputusan Untuk Menentukan Penerimaan Dana Santunan Sosial Anak Nagari Dan Penyalurannya Bagi Mahasiswa Dan Pelajar Kurang Mampu Di Kenagarian Barung - Barung Balantai Timur. Jurnal TEKNOIF, 3(2), 70-79. https://doi.org/23382724

[3] Fitriana, A. N., Harliana, H., \& Handaru, H. (2018). Sistem Pendukung Keputusan Untuk Menentukan Prestasi Akademik Siswa dengan Metode TOPSIS. Creative Information Technology Journal, 2(2), 153. https://doi.org/10.24076/citec.2015v2i2.45

[4] Hidayatullah, P., \& Kawistara, J. K. (2014). Pemrograman Web. Informatika Bandung, 3-231. https://doi.org/n

[5] Kadir, A. (2014). Pengenalan Sistem Informasi Edisi Revisi. Pengenalan Sistem Informasi Edisi Revisi. https://doi.org/10.13140/2.1.2637.6328

[6] Mallu, S. (2015). Sistem pendukung keputusan penentuan karyawan kontrak menjadi karyawan tetap menggunakan metode topsis. Jurnal Ilmiah Teknologi Dan Informasi Terapan, 1(2), 36-42.

[7] Mara Destiningrum, Q. J. A. (2017). SISTEM INFORMASI PENJADWALAN DOKTER BERBASSIS WEB DENGAN MENGGUNAKAN FRAMEWORK CODEIGNITER (STUDI KASUS: RUMAH SAKIT YUKUM MEDICAL CENTRE). TEKNOINFO, 11(2), 6-13. Retrieved from http://ejurnal.teknokrat.ac.id/index.php/teknoinfo/article/view/24

[8] Sukamto, R. A., \& Shalahuddin, M. (2016). Rekayasa Perangkat Lunak. Informatika Bandung.

[9] Sukamto, R. A., \& Shalahuddin, M. (2013). Modul Pembelajaran Rekayasa Perangkat Lunak (Terstruktur dan Berorientasi Obyek). Bandung: Modula (Vol. 53). https://doi.org/10.1017/CBO9781107415324.004

[10] Sutabri, T. (2012). Konsep Sistem Informasi. Konsep Sistem Informasi (Vol. 53). https://doi.org/10.1017/CBO9781107415324.004 